\title{
Working with values: an alternative approach to win-win
}

\section{Sarah Williams*}

Department of Strategy and Management, The Business School,

University of Bedfordshire, University Square, Luton, LU1 3JU, UK

Email: sarah.williams07@beds.ac.uk

*Corresponding author

\section{Diane Preston}

Department for People and Organisations The Faculty of Business and Law, The Open University Business School, Milton Keynes, MK7 6AA, England, UK Email: diane.preston@open.ac.uk

\begin{abstract}
In this paper we offer an alternative perspective on the business case for why organisations should embrace the arguments for corporate social responsibility (CSR). In particular we look at the 'win-win' scenario often posited by both internal and external agencies where it is not only the business who wins by adopting a CSR agenda but also the environment, 'save money save the planet'. Using a case study of a group of SME managers belonging to a Green Business Network in the UK, we offer a different approach to relying on the traditional win-win scenario that assumes businesses and managers are motivated largely by financial gain. Instead, we show how a series of workshops were used based on Schwartz's value system with the aim of helping the managers to, firstly understand their own values and motivations toward CSR and, secondly, how they could translate this to better understand the values of their own managers and colleagues with regard to embedding CSR practice. The aim of the paper is to highlight the value of taking a perspective on CSR at the individual level as well as offering a tool that managers could use in their own practice.
\end{abstract}

Keywords: corporate social responsibility; CSR; environmental engagement; values; motivation; engaging employees; small to medium business enterprises; SMEs.

Reference to this paper should be made as follows: Williams, S. and Preston, D. (xxxx) 'Working with values: an alternative approach to win-win', Int. J. Corporate Strategy and Social Responsibility, Vol. X, No. Y, pp.xxx-xxx.

Biographical notes: Sarah Williams is a Senior Lecturer in the University of Bedfordshire Business School. Her teaching and research interests focus on business sustainability and, in particular, the role of the individual. 
Diane Preston is a Senior Lecturer in the Department for People and Organisations at Open University Business School. Her teaching and research interests focus on management education and professionals moving into management.

\section{Introduction}

From sustainable development policies to increasing environmental awareness - and cynicism - from both businesses and their customers, a range of pressures have been imposed on the business sector to improve its environmental performance. Engaging employees at all levels of the organisation and motivating them to consider corporate environmental and social responsibility has been identified as one of the most challenging aspects of improving sustainability performance (Smith and Sharicz, 2011). Many agencies, including the European Union (CEC, 2011), promote the traditional 'win-win' business case where both organisation and environment win in a 'save money - save the planet' scenario. However this has been limited in its success (see, for example, Banergee, 2014; Brammer et al., 2012; Parker et al., 2010; Spence, 2007; Drake et al., 2004) perhaps because of its overriding focus on financial gain. The win-win approach assumes that businesses, managers and employees are primarily motivated by economic gain when it comes to getting involved in CSR. Similar to Grant et al. (2008), in their explanation of employee commitment coming from the opportunity to give support as well as to potentially receive, we argue here that a focus on self-interest over-simplifies understanding. In other words, individual values such as what Schwartz (1996) calls achievement and benevolence may also play a part in the decision to move to CSR. We suggest that work from the field of psychology can offer new insight into how humans draw on their values to develop personal motivations. In this we support the position of Seidler (2016) that an enlightened self-interest view of CSR engagement is incomplete. Finally, we outline a new way of working with, and analysing the feedback from, managers responsible for CSR based on the Schwartz value system (SVS).

The values that individuals draw on in making their decisions have been shown to be complex in nature. Rokeach (1968) argued that values underlie most aspects of society and culture whilst Schwartz (1996) identified that motivations for action are based on the interplay of a combination of values, rather than any one specific value acting alone.

Schwartz developed the SVS that has been used in various ways by researchers (for example, Chin et al., 2013; Feldman et al., 2015; Lönnqvist et al., 2013; Liu and Cohen, 2010) but usually forming the basis of a questionnaire allowing analysis of large scale quantitative data. The research outlined in this paper offers an alternative approach using Schwartz's framework as the basis of a qualitative intervention. The research is built on a series of workshops based on individual values with a group of managers who had responsibility for the environmental agenda within small to medium business enterprises (SMEs). Our interest is in developing this new approach and thereby challenging the assumption that financial gain is at the heart of the motivation for taking action and implementing change with regard to CSR. In establishing the range of values that managers draw on we can better understand what, if not purely economic gain and selfinterest, might motivate individuals to get involved in CSR at work. 


\section{Challenges to the win-win argument}

The primacy of bottom line benefits has been the focus of much CSR research and policy (Carroll and Shabana, 2010). For example, cost reduction and regulatory compliance are often cited as the main reasons for the move to CSR (Williamson et al., 2006). This preoccupation with the traditional win-win approach and the absence of a wider appreciation of societal benefits of CSR leads to what Banergee (2014) calls a 'tension' in organisational studies. Interestingly, the win-win approach is enshrined in EU strategy as a key way to engage SMEs in the goals of environmental protection and economic growth (Nilsson et al., 2009; Revell, 2003). An emphasis on resource efficiency and cost savings is the mainstay of the EU 2020 strategy (CEC, 2011). However, there have been criticisms of the effectiveness of win-win to engage businesses with environmental issues specifically, as well as CSR more generally. For example, in a report to the UK Government Vickers et al. (2009) concluded that the win-win idea was subject to ongoing doubt and a lack of responsiveness by SME managers. In addition, a major Economic and Social Research Council (ESRC) funded study in the UK (Revell and Blackburn, 2004) found that win-win approaches were insufficient for SME managers to be motivated to change their behaviour.

The academic literature around business greening also reports that SMEs respond to the win-win business case with scepticism (Cassells and Lewis, 2011; Spence, 2007; Simpson et al., 2004; Worthington and Patton, 2005; Vernon et al., 2003; Fineman, 2000). However, there is an apparent contradiction: SMEs have been shown to save money through environmental improvements and resource efficiency. For example, a report to the UK Department for Environment, Farming and Rural Affairs (DEFRA) showed that low cost and no cost actions could equate to $£ 23$ billion in UK business savings. Also that an environmental saving in terms of carbon reduction could equate to 29 million tonnes of carbon dioxide (Hollins, 2011). As a rejoinder, other research suggests that whilst larger SMEs have demonstrated financial savings through environmental improvements, these tended to be at the level of making short-term savings that required little or no investment (Worthington and Patton, 2005). There is an emerging argument that while SMEs do save money it is not the financial savings that motivate them and that any financial savings are a by-product of environmental actions taken for other reasons (Boiral et al., 2012; Cassells and Lewis, 2011; Spence, 2007). Despite this, the win-win argument is still the main message from policy makers (Calogirou et al., 2010; Spence, 2007) and the competing, value-led interpretation and demands on managers are largely absent from academic research (Hine and Preuss, 2009).

\section{The role of the manager and individual values}

Some literature related to CSR and business greening make reference to the values of the SME leader as being important in shaping the business approach to engagement with sustainability. However this usually refers to an environmental and/or altruistic orientation and is unclear about what is meant by values (Sonenshein et al., 2014; Escriba-Esteve et al., 2009). Some studies consider the values of the leader in relation to leadership style; for example, the implications for CSR of a transactional versus 
transformational leadership approach (Groves and LaRocca, 2011; Duarte, 2010; Jenkins, 2006; Waldman et al., 2006; Sosik, 2005). The broader issue of employee engagement with CSR activities and how the perception of a charismatic leadership style appears to promote positive behaviour and engagement is also explored by Pavlos et al. (2013). Yet this focus on leadership style still demonstrates a lack of focus on the understanding of the individual values associated with leadership and CSR (Groves and LaRocca, 2011). More recent research argues that win-win oversimplifies motivations to engage with CSR (Moran et al., 2013; Williams and Schaefer, 2013) and begins to look instead at the level of the individual and in particular the role of individual values. If managers are motivated by more than just a narrow concern for economic benefits to the business this suggests that to engage SMEs more fully in CSR, policy makers need to recognise the limitations of win-win and explore more sophisticated approaches. There are also some calls for research on the motivations for CSR to be grounded in the experience of the individual (Battisti and Perry, 2011; Onkila, 2009; Spence, 2007). Existing literature also tends to ignore the role of individual managers (Colwell and Joshi, 2013) in terms of the power of language and human interaction (Onkila, 2009; Hunt and Raman, 2000). These are important gaps in that the emotional, 'human factor' (Beauregard, 2010) can be argued to be the foundation for both personal and organisational performance. This acknowledges employee engagement with CSR as a complex and multifaceted construct influenced by both the business context and employee perceptions (Collier and Esteban, 2007). Research on individual values is then a 'pre-requisite for a deeper understanding' [Onkila, (2009), p.287] of how businesses interact with environmental issues. The contribution of this paper is to address the need to look at individual values and use the SVS as part of a qualitative research design (Williams et al., 2017). This should provide new insight into how managers make sense of CSR and other complex, socially constructed ideas such as climate change (Hulme, 2009).

\section{Using values to understand engagement}

There is a wide literature on values that could be used by researchers interested in how and why individuals engage with CSR and sustainability at work. This is based on the work of Rokeach (1968), who has been referred to as the 'father of modern values research' [Ralston et al., (2011), p.4]. Rokeach argued that research often focuses on attitudes rather than values largely because the former are easier to measure. He proposed that, firstly, individuals can hold many hundreds of attitudes but there are a much smaller number of values that underlie them and act as a filter to the information that individuals see, hear and act upon. Values relate to the deeper needs and motivations that guide individual behaviour and are therefore more clearly linked with personal goals and behaviour. Secondly, those values are relatively abstract and tend not to be tied to any one specific behaviour, object or situation. He suggests that values are expressed through belief statements about the world that cannot observed directly but can be inferred from what is said and done. For example, two individuals might express similar attitudes towards an idea but be drawing on entirely different central values. Once a value becomes central to an individual it is difficult for it to be challenged and becomes a guide to action and a standard that is used to justify and influence one's own and others' behaviour. Thirdly, Rokeach argued that values are organised within an individual as a personal system or hierarchy where some values are personally more important than 
others. This can mean that values are sometimes in tension with each other and, when a situation activates two or more opposing values, the individual will use their learnt prioritisation of values to make choices and resolve conflict.

It is useful to explore how the ideas of Rokeach could help us to understand managers' actions with regard to CSR. Taking the example of climate change and applying Rokeach's ideas suggests that how an individual sees such issues would be a reflection of what they believe it to be. So if the individual believes the world to be a dangerous and insecure place, they are likely to perceive climate change as threatening the end of the world. Seeing climate change as a threat is less likely if an individual believes that mankind is clever and adaptable and will survive because mankind always has. As Rokeach explained, the greater the perceived consequences for the individual, the greater the effort is made to resist change to centrally held beliefs. He argued that the majority of the values literature focused on peripheral beliefs and attitudes rather than centrally held values. In this paper, we argue that this can also be seen in the CSR and business greening literature even though theoretical understanding of values has moved forward in other areas. There are exceptions; some studies attempt to identify which values influence environmental behaviour (Henry and Dietz, 2012; Corraliza and Berenguer, 2000; Stern et al., 1999, Neuman, 1986). However these studies adopt a positivist methodology in order to report on the causal influences of particular values (that are treated as independent variables) on particular environmental actions.

Examples are recycling (Corraliza and Berenuer, 2000), energy efficiency (Mirosa et al., 2013; Poortinga et al., 2004; Neuman, 1986) and pro-environmental behaviour more generally (e.g., Stern and Dietz, 1994; Dunlap et al., 1983). Within these studies there seems to be agreement that environmental behaviours are linked with values but attempts to investigate how behaviour links with values have generated limited insights. For example, Neuman (1986) found there was a positive correlation related to environmental behaviour and beliefs but that pro-environmental values did not predict pro-environmental behaviour. A later study (Corraliza and Berenguer, 2000) concluded that behaviour with regard to the environment depends on the interconnection between values and situational variables and that there was apparent conflict between the two for individuals. There are other studies that look at this inconsistency from the perspective of a values - action gap with regard to environmental behaviour (Blake, 1999; Barr, 2006; Kollmuss and Agyeman, 2002; Flynn et al., 2009) but, as Kennedy et al. (2009) point out, they fail to focus on the perspective of the individual and in doing so underplay complexity. Businesses are after all made up of individual people and with regard to values people can behave very differently even under similar constraints and conditions (Kennedy et al., 2009). What is required is a greater appreciation of how individuals frame environmental issues and trade-off between competing priorities.

\section{Schwartz's value system}

The work of Shalom Schwartz builds on the ideas of Rokeach in two ways that are of interest to this study. Firstly Schwartz (see for example, Schwartz, 1996) identified ten groups of human values along with clear individual level marker values that help to define each value. For example, the self-enhancing value of power can be recognised through the need for wealth, social status/social power, control and authority. Secondly, 
Schwartz developed a relational 'circumplex' model (Schwartz and Boehnke, 2004) to demonstrate how the ten different individual level values conflict or complement each other across two axis - concern for self-verses concern for others, openness to change versus the need for conservation.

Figure 1 The Schwartz circumplex model

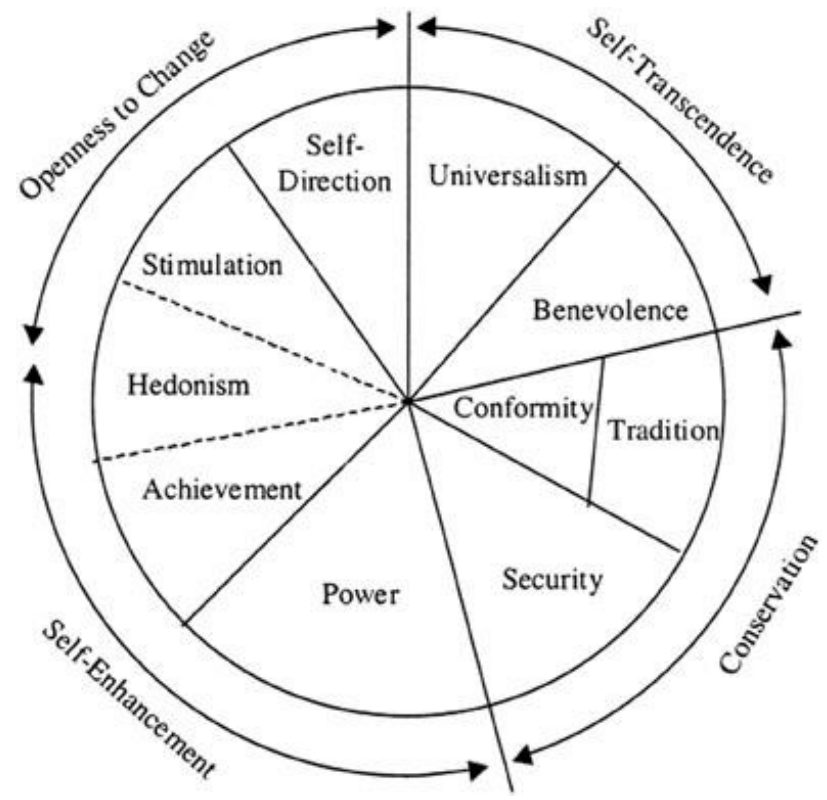

In a study of 50 different nations Ralston et al. (2011) demonstrated the reliability, validity and generalisability of the SVS and positioned the SVS as a well-defined construct relating to motivational needs. It provides a useful way of mapping, identifying and understanding the structure of individual human values regardless of culture. Continuing their work with the SVS, Ralston et al. (2014) went on to confirm the importance of values at an individual level as a predictor for ethical behaviour. While previous studies have predominantly taken a survey-based approach (Agle and Caldwell, 1994) some more recent studies (Mirosa et al., 2013; Crompton and Kasser, 2009; Onkila, 2009) have used the SVS as a framework for exploring values in a more interpretive way. We follow this lead based on a methodology that uses Schwartz's SVS as part of a qualitative approach to understanding the values and motivations of the individual manager.

\section{Methodology}

This paper draws on qualitative data from interviews plus workshop feedback from a group of managers who were members of a regional Green Business Network in the UK. The study was designed to explore the often under-reported 'lived' experiences of individuals who find themselves with the responsibility of implementing CSR throughout 
their organisations and persuading staff at all levels of its benefits. The study was longitudinal in that the workshops and interviews were sequential with data from each informing the design of the next stage.

\subsection{Stage 1: initial interviews}

Interviews were held with 31 senior SME managers in the eastern 'Anglian' region of the UK. Narrative Analysis (see for example, Wiles, 2005) was used with codes based on the SVS to explore what values could be ascertained through managers' talk. The interviews explored how managers made sense of their environmental approach at work including their reasons for acting and the actions they took. Following this, the study continued by working with an additional group of 20 managers belonging to the Bedfordshire Green Business Network to explore how a qualitative approach to understanding values could be used by them in their organisations to engage staff with environmental issues.

During the initial interviews [see Williams et al. (2017) for detail], the individual level values and their associated individual level marker values were used to code interview data. This method of attempting to access values via narrative is very much in the tradition of Rokeach who used narrative samples to check the consistency of his values theory by counting references to 'freedom' and 'equality' (1968, p.171) and went on to give in-principle support for qualitative methods as a way of 'reliably identifying' values (1979, p.58). In order to recognise both the explicit and 'hidden meanings' in this study, a decision was made not to use an electronic coding tool such as Nvivo. This allowed for immersion in the data and growing awareness of the subtle differences and nuances that can be lost using electronic systems (Wiles et al., 2005).

\subsection{Stage 2: a series of five workshops}

The longitudinal aspect of this study comes from a series of five workshops that were carried out over three years (February 2012 to April 2015) with a core group of 20 managers from the Bedfordshire Green Business Network. Each two-hour workshop included facilitated presentations, discussions and group exercises.

\subsubsection{Workshop one - adapting your business to climate change}

The aim of the first workshop (February 2012) was to help managers to move beyond quick CSR wins to thinking about how environmental actions could contribute to building the resilience of the business. The intention was to apply a values-based approach to reframing CSR - and more specifically climate change - from values based on what Schwartz labels as Power (that is, save money, increase profit, improve competitive advantage and social status) into values Schwartz calls Achievement (making a difference, efficiency, effectiveness, social recognition).

The workshop began by addressing individual and group assumptions about climate change. This was followed by discussions about, firstly, the scientific basis for the human role in climate change and secondly, how values may help individuals to filter, frame and construct climate change and thereby motivate particular forms of engagement. Climate change was then deliberately reframed into the language of 'achievement' and presented as a model for engagement. This was done by breaking climate change into the components of challenge (managerial, technical, and accounting), efficiency and 
effectiveness. Managers were asked to consider ways in which they felt that they could make a difference at work in all three areas.

For the next part of the workshop managers were introduced to what we called the MAR model: mitigation, adaption and resilience. Mitigation was framed as reducing the impact of the business due to its use of carbon to stimulate efficiency values; Adaptation was equated to reducing the reliance of the business on sources of carbon to stimulate effectiveness and self-sufficiency values, and resilience was shown as seeing the longer term view and having the right conversations, thereby stimulating influencing (making a difference) values. We asked the managers to map their current approaches to climate change against the MAR model with the intention of encouraging them to think about climate change through different value sets. For example, where climate change was seen as a threat, mitigation could be reducing impact as well as resource requirements, adaptation about improving supply chain security and resilience about being part of the conversation. Where climate change was seen as a business opportunity mitigation and adaptation could be seen as getting one's own house in order and resilience about thinking ahead about what customers are likely to want from the business. Managers reported that they had not thought about their engagement with climate change in this way and that it helped them to see where they were making a difference and how and where they could focus longer term efforts.

Managers attending the first workshop asked whether the values-based approach could help them engage the board and staff in their organisations with environmental issues. This question is taken forward in the subsequent workshops.

\subsubsection{Workshops two to four - pressing the reset button}

Following the first workshop the authors were asked to provide three additional workshops that would help managers understand how values could help them engage their Boards and staff with CSR. The Board is an important anchor point that enables the firm to take a more strategic approach to CSR (Bryan-Kjær, 2017). Board and staff engagement is also considered integral to the revised international Environmental Management Standard ISO14001:2015 (BSI, 2015). In preparation for this four interviews were carried out with key members of the Bedfordshire Green Business Network to explore how they engaged staff and their own use of both implicit and explicit values at work. Workshops two to four were then designed as a series that would sequentially develop the ideas of attendees. The first of these three sessions (May 2014) looked to apply values-based ideas to engaging employees with environmental change by thinking about the messages that managers were using. That is acknowledging the implicit use of values in existing messages (and identifying those values) and then looking to make the use of values explicit.

The 'pressing the reset button' model was presented to members at the first session, whereby a series of prompts were used to help members map each step of the engagement process. The 'why' was presented as the missing link that started with understanding their own reasons for being involved with the company's environmental project and spread to the use of values-based ideas to understand and engage the board and staff. The SVS was explained to attendees and they were given the opportunity to complete a simple version of the SVS (Appendix 1). The questionnaire designed by the authors was based on the individual level marker values (Ralston et al., 2011), and proved successful in helping the managers to explore their own value assumptions. The 
questionnaire was used as a tool for them to discuss values and how that related to their engagement of environmental issues at work with other participants in the workshop.

Figure 2 Pressing the reset button

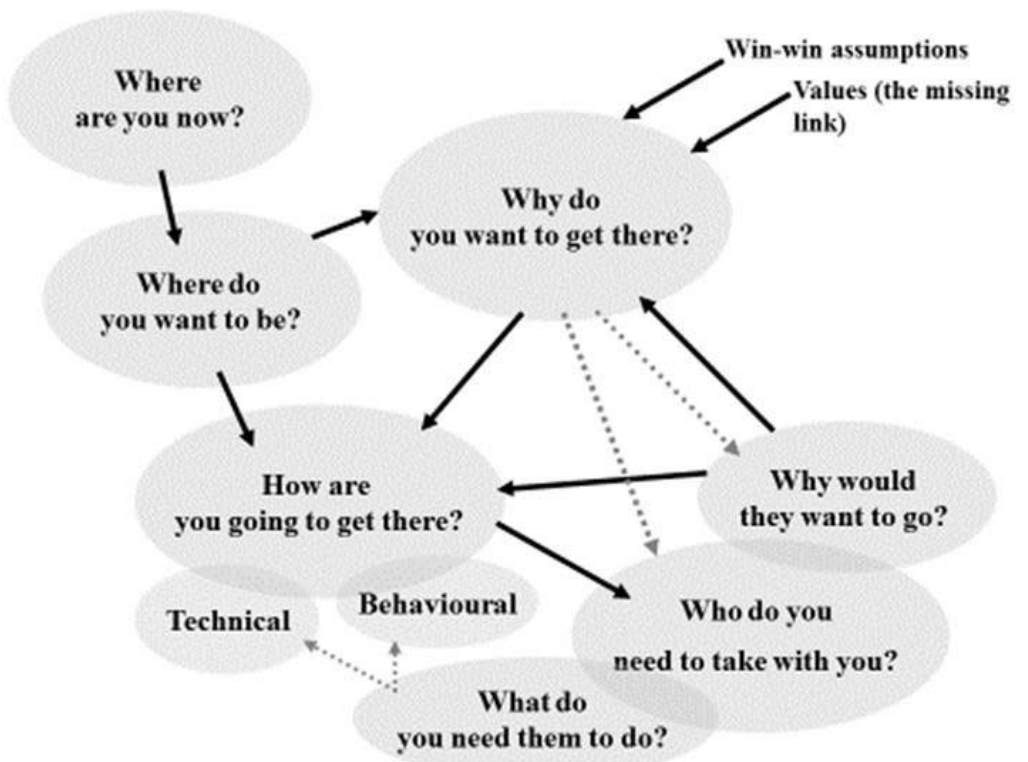

The second of the three workshops (June 2014), looked at climate change as a complex environmental issue that staff were likely to be both aware of and to hold pre-existing constructions about. It was acknowledged by attendees that the way staff think about climate change would be filtered and framed through their values and that this would affect their motivation (or rejection) of messages to act at work. The SVS was again used to help managers think about how key staff or directors framed climate change based on the language they used.

The third workshop (July 2014) explored values as the root of behaviour and the role of values in motivation and resistance to change. Example texts from the initial interviews (see Williams et al., 2017) were used to help managers recognise values in real life talk and to explore how easy it was to make assumptions based on their own values and ways of seeing the world.

\section{- Example 1:}

"I'm personally not entirely convinced of the arguments behind carbon as the driver of climate change. Now that's not to say that we should just ignore it. We can't operate a global economy based on oil and fossil fuels because they're going to run out, so for me the argument about climate change being driven by human activity, I feel the jury is out. But we can't just carry on doing what we're doing, absolutely not. It's not going to work, it's not going to provide a world to my grandchildren, let alone my children, in which there are the resources to enjoy our current living standards. So we have to do something. When it comes down to it, we can't continue consuming as much energy as we currently do, from the sources that we currently take it from”. 
- $\quad$ Example 2:

"It's very obvious that non-renewable energy resources are being depleted, that environments are under threat, that climate change is happening in some ways, that it will affect populations. I suppose the more greedy we are for fossil fuels the more disadvantaged the poor get, so it's the actual changes to the weather that are important but its probably a bigger picture of the effect on the poor, the poor of the world really, which is probably the more moral way of looking at it. Undoubtedly there's people who are living on the edge, who will be pushed off the edge by the greed of developed countries and the wrath of the developing countries for resources, so I think it’s a moral question”.

In both examples, climate change is seen to be linked with energy. In example 1 this relates to oil running out even though the case for the human role in climate change is not fully accepted. The notion that 'we' cannot carry on with business as usual dependent on a resource that will run out implies that achievement (efficiency) may be important. However, the call to act is seen in why this is important: the manager is motivated by concern for the future of his children. This equates to what Schwartz describes as Benevolence (concern for the welfare of others, loyal, honest, and dependable). In the second example, the manager also frames climate change in terms of oil running out but the concern is much wider, drawing on Schwartz' Universalism values (social justice, environmental protection, equality, unity with nature) by relating morally to the poor of the world even though they are unknown personally.

\subsubsection{Final workshop - obtaining staff and management buy-in}

The fifth and final workshop (April 2015) was designed as a response to feedback from the previous session. Managers asked for help in practicing the use of values, particularly in recognising when colleagues might be drawing on values and how to use that to support their conversations. The session used two key exercises. The first helped managers to practice ‘tuning-in' to values by developing their listening skills. Managers worked in pairs to discuss ideas from a prescribed list of topics while being primed for the SVS individual level marker values. In the second exercise managers used their interpretation from the first exercise to frame an energy engagement project into language that would motivate their colleague.

\section{Findings}

Drawing on the workshops in relation to values-based ideas, the following key findings can be highlighted:

- The importance of management support and consistency between policy and action was emphasised with the need for appropriate 'carrots and sticks' to be built into processes. That is where 'good' CSR practices are embedded into what is expected and rewarded according to the values of the organisation and the needs of individuals. As an example, competition and social status might engage power motivated individuals but opportunities to work together, or to make a difference, might appeal to individuals with stronger Benevolence or Achievement values. 
- Individual managers make implicit value-based assumptions about what motivates colleagues and other members. The SVS was a useful and easily understood tool for managers attending the workshops to reflect on their own sensemaking and recognise the different values that each was drawing on in framing CSR related examples.

- It was acknowledged that it was possible to 'tune in to values' using the SVS and that this enabled managers to make time to save time by increasing effectiveness. It was generally acknowledged that use of value-based ideas enabled managers to pick up on what people are demonstrating as important to them allowing managers to help individuals to meet their needs at work.

- Although workshop attendees talked about wanting to engage staff with CSR it was clear that taking a more strategic approach that included clear reflection on 'where we are now', 'where we want to go' and 'why we want to go there' would allow a clear value framing and commitment.

- Contrary to the assumptions underlying win-win, senior management are not just interested in profit and wealth; part of the challenge of the CSR manager is to find out what else motivates Board members as individuals. In addition to getting to understand what motivates the senior management team it is important to identify other key people, listen to them and get to understand what they need in order to meet their needs by delivering the environmental agenda. The SVS can be a useful tool in achieving this understanding.

- Management examples from the workshops illustrated the importance of using multiple ideas and motivations ensuring that ideas from the same (or complimentary) value groups are used and conflicting values avoided. For example, walking to work week can be promoted to staff as being about health, friendship, good neighbours, and making a difference to community together. Although the environmental manager may also want to record savings in fuel costs this would introduce powerbased ideas into a message that is otherwise based on Benevolence and Achievement and so should be avoided.

- The importance of social recognition (within Achievement) was acknowledged and how this is different from 'green awards' that reflect competition (a Power value). Recognition can be through appraisal, 'you're doing a good job’, promotion and the opportunity to do more of what is being done well.

Finally, in the discussions within the workshop series, managers described how they could recognise their own values and those of other key colleagues in the SVS narratives. They reported a willingness and ability to use the SVS individual level markers to recognise the values of staff and Board members and to reframe their own messages to them in order to stimulate their existing values and motivate them towards desired environmental behaviours. Managers also reported that it was clear the approach could be used more generally to support and motivate staff by recognising what was important to them. Managers suggested that the approach could support existing engagement techniques that point towards 'what' to do with a clear 'how' to. For example, in identifying and engaging key individuals to join a green team and in supporting them to cascade engagement within their own staff groups. 


\section{Discussion and conclusions}

This paper has described how taking a different approach to working with managers can help them engage staff with CSR at work. A series of workshops and interviews that informed one another formed the basis of a qualitative approach where the focus was on raising awareness of personal values. This was based on the established SVS model (Schwartz, 1996; Schwartz and Boehnke, 2004) and proved to be a useful tool for helping participant managers to understand their own and others values' and their potential influence on behaviours related to CSR. We argue that this research makes a contribution to both the existing CSR literature and provides an additional resource for managers to use in the complex task of engaging others in CSR at work. Focussing on their own values, managers saw the benefits of thinking about CSR at an individual level for both themselves and others. Participants in the workshops reported that they did not find the approach over-complicated and saw the potential for it to be used as a tool more generally for understanding the complexity of individual staff motivation and engagement.

These findings call on policy-makers to challenge the assumptions about values within the traditional win-win approach with regard to CSR in terms of a its potential over-simplification and contradictions that can limit - or even deter - management engagement. 'Win-win' sends out a shallow, conflicting message and potentially ignores those managers who are not motivated primarily by this overly simple equation. In Schwartz's terms, the simple win-win message ignores the other values that individual managers draw on such as benevolence and security. By engaging explicitly with CSR as a value issue policy makers and facilitators could encourage individuals at all levels in an organisation to address their own values and assumptions. In doing so there will be more acknowledgements that CSR at work and environmental aspects such as climate change are in fact multi-faceted social ideas as well as physical phenomena. This alone may help individuals to explore their own sense making and be motivated to act in a way that is congruent with their values. The continued policy focus on win-win underplays understanding at the individual level, actively limits the discussion on values and makes the erroneous assumption that 'values' means environmental values only. In this way it continues to place limits on the potential for SME engagement with CSR at all levels.

\section{References}

Agle, B.A. and Caldwell, C.B. (1994) 'Understanding research on values in business: a level of analysis framework', Business and Society, Vol. 38, No.3, pp.326-387.

Banergee, S.B. (2014) 'A critical perspective on CSR: towards a global governance framework', Critical Perspectives on International Business, Vol. 10, Nos. 1-2, pp.84-95.

Barr, S. (2006) 'Environmental action in the home: investigating the value action gap', Geography, Vol. 91, No. 1, pp.43-54.

Battisti, M. and Perry, M. (2011) 'Walking the talk? Environmental responsibility from the perspective of small-business owners', Corporate Social Responsibility and Environmental Management, Vol. 18, No. 3, pp.172-185.

Beauregard, T.A. (2010) 'Introduction: the import of intrapersonal and interpersonal dynamics in work performance', British Journal of Management, Vol. 21, No. 2, pp.255-261.

Blake, J. (1999) 'Overcoming the 'value action gap' in environmental policy: tensions between national policy and local experience', Local Environment, Vol. 4, No. 3, pp.257-278. 
Boiral, O., Henri, J.F. and Talbot, D. (2012) 'Modeling the impacts of corporate commitment on climate change', Business Strategy and the Environment, Vol. 21, No. 8, pp.495-516.

Brammer, S., Hoejmose, S. and Marchant, K. (2012) 'Environmental management in SMEs in the UK: practices, pressures and perceived benefits', Business Strategy and the Environment, Vol. 21, No. 7, pp.423-434.

Bryan-Kjær, K. (2017) 'Sustainability in the hierarchy: how corporate sustainability is anchored in the organisational structure', International Journal of Corporate Strategy and Social Responsibility, Vol. 1, No. 2, pp.179-192.

BSI (2015) British Standards Institute (BSI) ISO 14001:2015 Pre-course Reading [online] https://www.bsigroup.com/LocalFiles/en-GB/iso-14001/training/BSI-pre-course-reading_ EMS04101ENGX-EN-UK.pdf. (accessed August 2017).

Calogirou, C., Sørensen, S.Y., Bjørn Larsen, P. and Alexopoulou, S. (2010) SMEs and the environment in the European Union. PLANET SA and Danish Technological Institute for European Commission, DG Enterprise and Industry [online] http://ec.europa.eu/enterprise/ policies/sme/business-environment/files/main_report_en.pdf. (accessed 31 December 2012).

Carroll, A.B. and Shabana, K.M. (2010) 'The business case for corporate social responsibility: a review of concepts, research and practice', International Journal of Management Reviews, Vol. 12, No. 1, pp.85-105.

Cassells, S. and Lewis, K. (2011) 'SMEs and environmental responsibility: do actions reflect attitudes?', Corporate Social Responsibility and Environmental Management, Vol. 18, No. 3, pp.186-199.

CEC (2011) ‘Resource-efficient Europe - flagship initiative under the Europe 2020 strategy’, COM 2011: 12, Eur. Comm., Brussels.

Chin, M.K., Hambrick, D.C. and Treviño, L.K. (2013) 'Political ideologies of CEOs: the influence of executives' values on corporate social responsibility', Administrative Science Quarterly, Vol. 58, No. 2, pp.197-232.

Collier, J. and Esteban, R. (2007) 'Corporate social responsibility and employee commitment', Business Ethics: A European Review, Vol. 16, No. 1, pp.19-33.

Colwell, S.R. and Joshi, A.W. (2013) 'Corporate ecological responsiveness: antecedent effects of institutional pressure and top management commitment and their impact on organizational performance', Business Strategy and the Environment, Vol. 22, No. 2, pp.73-91.

Corraliza, J.A. and Berenguer, J. (2000) 'Environmental values, beliefs and actions: a situational approach', Environment and Behavior, Vol. 32, No. 6, pp.832-848.

Crompton, T. and Kasser, T. (2009) Meeting Environmental Challenges: The Role of Human Identity, pp.1-93, WWF-UK, Godalming, UK.

Drake, F., Purvis, M. and Hunt, J. (2004) 'Meeting the environmental challenge: a case of win-win or lose-win? A study of the UK baking and refrigeration industries', Business Strategy and the Environment, Vol. 13, No. 3, pp.172.

Duarte, F. (2010) 'Working with corporate social responsibility in Brazilian companies: the role of managers' values in the maintenance of CSR cultures', Journal of Business Ethics, Vol. 96, No. 3, pp.355-368.

Dunlap, R.E., Grieneek, J.K. and Rokeach, M. (1983) 'Human values and pro-environmental behaviour', in Conn, W.D. (Ed.) Energy and Material Resources: Attitudes, Values and Public Policy, Boulder Co. Westview Press, Boulder, Colorado.

Escriba-Esteve, A., Sanchez-Peinado, L. and Sanchez-Pienado, E. (2009) 'The influence of top management teams in the strategic orientation and performance of small and medium sized enterprises', British Journal of Management, Vol. 20, No. 4, pp.581-597.

Feldman, G., Chao, M.M., Farh, J.L. and Bardi, A. (2015) 'The motivation and inhibition of breaking the rules: personal values structures predict unethicality', Journal of Research in Personality, December, Vol. 59, pp.69-80.

Fineman, S. (2000) The Business of Greening, Routledge, London. 
Flynn, R., Bellaby, P. and Ricci, M. (2009) 'The 'value action gap' in public attitudes towards sustainable energy: the case of hydrogen energy', The Sociological Review, Vol. 57, No. 2, pp.159-180.

Grant, A.M., Dutton, J.E. and Rosso, B.D. (2008) 'Giving commitment: employee support programs and the prosocial sensemaking process’, Academy of Management Journal, Vol. 53, No. 5, pp.898-918.

Groves, K.S. and LaRocca, M.A. (2011) 'An empirical study of leader ethical values, transformational and transactional leadership and follower attitudes toward corporate social responsibility', Journal of Business Ethics, Vol. 103, No. 4, pp.511-528.

Henry, A.D. and Dietz, T. (2012) 'Understanding environmental cognition', Organization and Environment, Vol. 25, No. 3, pp.238-258.

Hine, J.A. and Preuss, L. (2009) ' 'Society is out there, organisation is in here': on the perceptions of corporate social responsibility held by different managerial groups', Journal of Business Ethics, Vol. 88, No. 2, pp.381-393.

Hollins, O. (2011) The Further Benefits of Business Resource Efficiency, Department for environment, Food and Rural Affairs, London, UK.

Hulme, M. (2009) Why We Disagree About Climate Change: Understanding Controversy, Inaction and Opportunity, Cambridge University Press, Cambridge.

Hunt, J. and Raman, S. (2000) 'Regulation matters: global environmental discourse and business response', in Fineman, S. (Ed.): (2002) The Business of Greening, pp.114-133, Routledge, London.

Jenkins, H. (2006) 'Small business champions for corporate social responsibility', Journal of Business Ethics, Vol. 67 No. 3, pp.241-256.

Kennedy, E.H., Beckley, T.M., McFarlane, B.L. and Nadeau, S. (2009) 'Why we don't "walk the talk": understanding the environmental values/behaviour gap in Canada', Human Ecology Review, Vol. 16, No. 2, pp.151-160.

Kollmuss, A. and Agyeman, J. (2002) 'Mind the gap: why do people act environmentally and what are the barriers to pro-environmental behaviours', Environmental Education Research, Vol. 8, No. 3, pp.240-260.

Liu, Y. and Cohen, A. (2010) 'Values, commitment and OCB among Chinese employees', International Journal of Intercultural Relations, Vol. 34, No. 5, pp.493-506.

Lönnqvist, J.E., Verkasalo, M., Wichardt, P.C. and Walkowitz, G. (2013) 'Personal values and prosocial behaviour in strategic interactions: Distinguishing value-expressive from valueambivalent behaviours', European Journal of Social Psychology, Vol. 43, No. 6, pp.554-569.

Mirosa, M., Lawson, R. and Gnoth, D. (2013) 'Linking personal values to energy-efficient behaviors in the home', Environment and Behavior, Vol. 45, No. 4, pp.455-475.

Moran, D., Lucas, A. and Barnes, A. (2013) 'Mitigation win-win', Nature Climate Change, Vol. 3, No. 7, pp.611-613.

Neuman, K. (1986) 'Personal values and commitment to energy conservation', Environment and Behavior, Vol. 18, No. 1, pp.53-74.

Nilsson, M., Varnäs, A., Kehler Siebert, C., Nilsson, L.J., Nykvist, B. and Ericsson, K. (2009) A European Eco-Efficient Economy: Governing Climate, Energy and Competitiveness, Report for the 2009 Swedish Presidency of the Council of the European Union, SEI.

Onkila, T.J. (2009) 'Corporate argumentation for acceptability: reflections of environmental values and stakeholder relations in corporate environmental statements', Journal of Business Ethics, Vol. 87, No. 2, pp.285-298.

Parker, S.K., Bindl, U.K. and Strauss, K. (2010) 'Making things happen: a model of proactive motivation', Journal of Management, Vol. 36, No. 4, pp.827-856.

Pavlos, A.V., Panagopoulos, N.G. and Rapp, A.A. (2013) 'Feeling good by doing good: employee CSR-induced attributions, job satisfaction and the role of charismatic leadership', Journal of Business Ethics, Vol. 118, No. 3, pp.577-588. 
Poortinga, W., Steg, L. and Vlek, C. (2004) 'Values, environmental concern and environmental behavior a study into household energy use', Environment and Behavior, Vol. 36, No. 1, pp.70-93.

Ralston, D.A., Egri, C.P., Furrer, O., Kuo, M.H., Li, Y., Wangenheim, F., Dabic, M., Naoumova, I., Shimizu, K., de la Garza Carranza, M.T. and Fu, P.P. (2014) 'Societal-level versus individual-level predictions of ethical behavior: a 48-society study of collectivism and individualism', Journal of Business Ethics, Vol. 122, No. 2, pp.283-306.

Ralston, D.A., Egri, C.P., Reynaud, E., Srinivasan, N., Furrer, O., Brock, D. and Fan, Y. (2011) 'A twenty-first century assessment of values across the global workforce', Journal of Business Ethics, Vol. 104, No. 1, pp.1-31.

Revell, A. (2003) 'The ecological modernisation of small firms in the UK', paper presented at the Business Strategy and Environment Conference, 16 September 2003, Leicester.

Revell, A. and Blackburn, R. (2004) SMEs and their Response to Environmental Issues in the UK, Kingston Business School, Kingston University.

Rokeach, M. (1968) Beliefs, Attitudes and Values: A Theory of Organisation and Change, Jossey-Bass, San Francisco.

Rokeach, M. (1979) Understanding Human Values: Individual and Societal, Collier Macmillan, London.

Schwartz, S. (1996) 'Value priorities and behavior: applying a theory of integrated value systems', in Seligman, U.C., Olson, J.M. and Zanna, M.P. (Eds.): The Ontario Symposium: The Psychology of Values, Vol. 8.

Schwartz, S.H. and Boehnke, K. (2004) 'Evaluating the structure of human values with confirmatory factor analysis', Journal of Research in Personality, Vol. 38, No. 3, pp.230-255.

Seidler, R.R. (2016) 'What to make of unprofitable corporate social responsibility', International Journal of Corporate Strategy and Social Responsibility, Vol. 1, No. 1, pp.65-85.

Simpson, M., Taylor, N. and Barker, K. (2004) 'Environmental responsibility in SMEs: does it deliver competitive advantage?', Business Strategy and the Environment, Vol. 13, No. 3, pp.156-171.

Smith, P.A. and Sharicz, C. (2011) 'The shift needed for sustainability', The Learning Organization, Vol. 18, No. 1, pp.73-86.

Sonenshein, S., De Celles K.A. and Dutton, J.E. (2014) 'It's not easy being green: the role of selfevaluations in explaining support of environmental issues', Academy of Management Journal, Vol. 57, No. 1, pp.7-37.

Sosik, J. (2005) 'The role of personal values in the charismatic leadership of corporate managers: a model and preliminary field study’, Leadership Quarterly, Vol. 16, No. 2, pp.221-244.

Spence, L.J. (2007) 'CSR and small business in a European policy context: the five 'C's of CSR and small business research agenda 2007’, Business and Society Review, Vol. 112, No. 4, pp.533-552.

Stern, P.C. and Dietz, T. (1994) 'The value basis of environmental concern', Journal of Social Issues, Vol. 50, No. 3, pp.65-84.

Stern, P.C., Dietz. T., Abel, T., Guagnano, G.A. and Kalof, L. (1999) 'A value-belief-norm theory of support for social movements: the case of environmentalism', Human Ecology Review, Vol. 6, No. 2, pp.81-97.

Vernon, J., Essex, S., Pinder, D. and Curry, K. (2003) 'The 'greening' of tourism micro-businesses: outcomes of focus group investigations in South East Cornwall', Business Strategy and the Environment, Vol. 12, No. 1, pp.49-69.

Vickers, I., Vaze, P, Corr, L., Kasparova, E. and Lyon, F. (2009) SMEs in a Low Carbon Economy: Final Report for BERR Enterprise Directorate [online] https://www.berr.gov.uk/files/ file49761.doc (accessed 7 July 2010). 
Waldman, D.A., Siegel, D.S. and Javidan, M. (2006) 'Components of CEO transformational leadership and corporate social responsibility', Journal of Management Studies, Vol. 43, No. 8, pp.1703-1725.

Wiles, J.L., Rosenberg, M.W. and Kearns, R.A. (2005) 'Narrative analysis as a strategy for understanding interview talk in geographic research’, Area, Vol. 37, No. 1, pp.89-99.

Williams, S. and Schaefer, A. (2013) 'Small and medium-sized enterprises and sustainability: managers' values and engagement with environmental and climate change issues', Business Strategy and the Environment, Vol. 22, No. 3, pp.173-186.

Williams, S., Schaefer, A. and Blundel, R. (2017) 'Understanding value conflict to engage SME managers with business greening', in Rendtorff, J.D. (Ed.): Perspectives on Philosophy of Management and Business Ethics, pp.73-91, Springer International Publishing, Cham, Switzerland.

Williamson, D., Lynch-Wood, G. and Ramsay, J. (2006) 'Drivers of environmental behaviour in manufacturing SMEs and the implications for CSR', Journal of Business Ethics, Vol. 67, No. 3, pp.317-330.

Worthington, I. and Patton, D. (2005) 'Strategic intent in the management of the green environment within SMEs: an analysis of the UK screen-printing sector', Long Range Planning, Vol. 38, No. 2, pp.197-212.

\section{Appendix 1}

Simple SVS Questionnaire based on the 'individual level marker values' of the SVS designed to stimulate self-reflection and discussion with managers and students

Instructions: Read through the different values. Choose the 16 that you feel mean the most to you. There are no right or wrong answers - everyone is motivated by all of these values. But it is about priorities and what matters most to you.

When you have marked up to 16 values, transfer the number of crosses that you have for each section to the Schwartz Circumplex Model. You may, or may not, like to discuss how the pattern of your model compares with those around you.

\section{What's in it for me? (Self-enhancing)}

I like to feel a sense of social power, that I'm in control or have Transfer the number of authority over others crosses to POWER

It's about wealth, material possessions and money

I like to have authority and the right to lead and command others

It's important that I preserve my public image/face

I am ambitious and enjoy working hard and aspiring to do better

I like to feel I can make a difference, that I am influential and can have an impact on people and events

Transfer the number of crosses to ACHIEVEMENT

Its important that I do a job well and that I'm recognised as capable, competent, effective, efficient

I like to be successful and to achieve goals

I am motivated by pleasure and the gratification of desires

It's about enjoying life, food, sex, leisure, etc.

I am self- indulgent, and focus on doing pleasant things
Transfer number of crosses to HEDONISM 


\section{Concern for others (self-transcendence)}

\begin{tabular}{ll}
\hline $\begin{array}{l}\text { Loyalty is important to me and I am faithful to my friends, } \\
\text { group }\end{array}$ & $\begin{array}{l}\text { Transfer number of } \\
\text { crosses to } \\
\text { BENEVOLENCE }\end{array}$ \\
I am honest, genuine, sincere and expect that in others & \\
I like to feel helpful and that I am working for the welfare of \\
others
\end{tabular}

\section{Protecting how things are (conservation)}

I have respect for tradition and want to preserve time honoured customs

I am moderate and prefer to avoid extremes of feeling or action

Transfer number of crosses to TRADITION

I am humble, modest, self-effacing

I accepting my portion in life and will submit to life's circumstances

I am devout, holding to religious faith and belief

I am polite and courtesy and good manners matter to me

I value self-discipline, self-restraint, resistance to temptation

I honour my parents and elders and showing respect matters

I am obedient, dutiful, and would prioritise meeting obligations

Social order and the stability of society are important to me

National security, protection of my nation from enemies matters

The reciprocation of favours and the avoidance of indebtedness is important

Family security, safety for loved ones is a priority

I like to be clean, neat and tidy and respect that in others
Transfer number of crosses to CONFORMITY

Transfer number of crosses to SECURITY 


\section{Openness to change}

I want an exciting life full of stimulating experiences

I want a varied life, filled with challenge, novelty and change

Transfer number of

I seek daring, adventure and risk

I need to have freedom of action and thoughts

I want to use my own creativity, uniqueness and Imagination to understand and solve problems

crosses to

STIMULATION

Transfer number of crosses to SELF-

I want to be independent self-reliant, self-sufficient

I need to choose my own goals, and select my own purposes

I am curious and interested in everything, I need to explore and find my own way 